\title{
Chronic Subdural Hematoma Revealing Skull Metastasis
}

\author{
Abad Cherif El Asri, Brahim El Mostarchid, Ali Akhaddar and Mohamed Boucetta
}

Key words: subdural chronic hematoma, skull, breast

(Intern Med 50: 791, 2011)

(DOI: 10.2169/internalmedicine.50.4654)
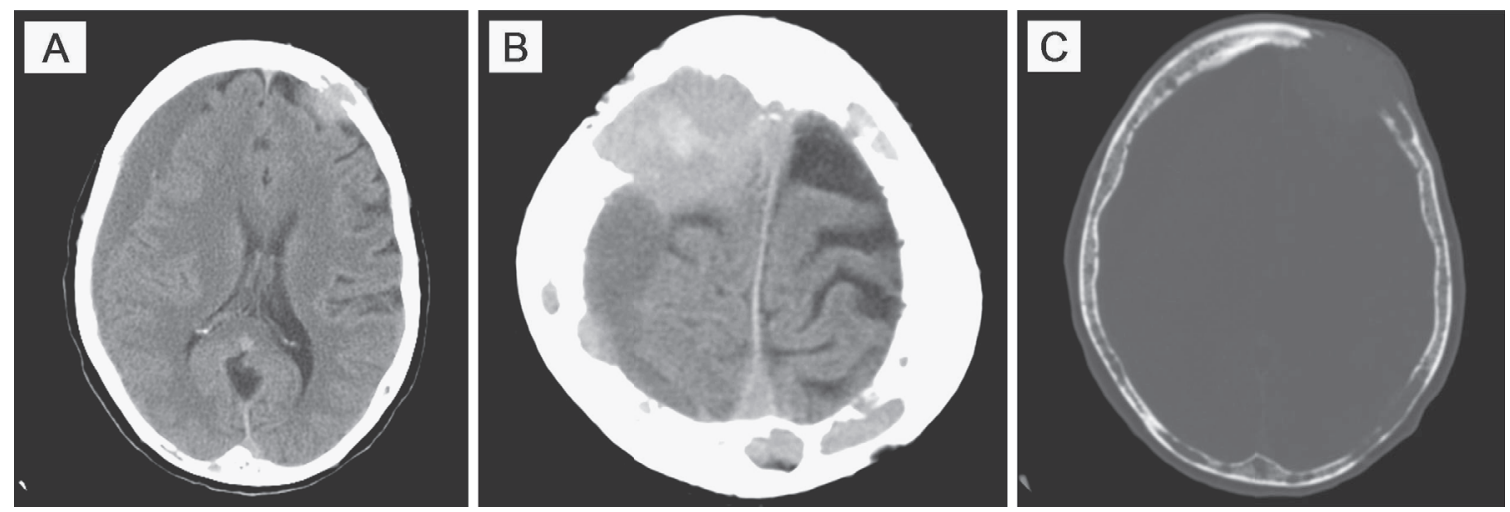

Picture 1.

This 64-year-old woman without any history of cancer or head trauma presented to the emergency department with a 10-day history of headache and weakness of her left limbs. On clinical examination, the patient was conscious with left hemiparesis. Cranial CT scan revealed multiple cranial osteolytic lesions associated with the imaging features of right fronto-parietal subdural chronic hematoma (Picture 1).

The patient was operated in emergency. A chronic hematoma was evacuated and a granulation tissue having a tough texture was biopsied. Histological findings demonstrated a dural metastasis from breast cancer. The mammography revealed a mass, with an irregular border, of the left breast which was biopsed. Histological findings demonstrated a poorly differentiated breast carcinoma (grade 3). Thoracoabdominal CT-scan and bone scintigraphy showed multiple metastatic lesions. The patient underwent palliative radiotherapy and chemotherapy and died 3 months later.

It is extremely rare for chronic subdural hematoma to be the first manifestation of breast cancer. When the diagnosis was confirmed, the prognosis of cancer was realized $(1,2)$.

The authors state that they have no Conflict of Interest (COI).

\section{References}

1. McKenzie CR, Rengachary SS, McGregor DH, Dixon AY, Suskind DL. Subdural hematoma associated with metastatic neoplasms. Neurosurgery 27: 619-624, 1990.

2. Laigle-Donadey F, Taillibert S, Mokhtari K, Hildebrand J, Delattre J-Y. Dural metastases. J Neuro-Oncol 75: 57-61, 2005. 